\title{
Management of patients with clinical stage I nonseminomatous germ cell testicular cancer: Active surveillance versus adjuvant chemotherapy - single-centre experience
}

\author{
D. ONDRUS ${ }^{1, *}$, M. ONDRUSOVA ${ }^{2,3}$, K. KAJO ${ }^{4}$ \\ ${ }^{1} 1^{\text {st }}$ Department of Oncology, Comenius University Faculty of Medicine, St. Elisabeth Cancer Institute, Bratislava, Slovak Republic; ${ }^{2}$ St. Elizabeth \\ University of Health and Social Sciences, Bratislava, Slovak Republic; ${ }^{3}$ Cancer Research Institute, Slovak Academy of Sciences, Bratislava, Slovak \\ Republic; ${ }^{4}$ Department of Pathology, Slovak Medical University, St. Elisabeth Cancer Institute, Bratislava, Slovak Republic
}

*Correspondence: dalibor.ondrus@ousa.sk

Received February 17, 2014 / Received April 9, 2014

\begin{abstract}
Surveillance after orchiectomy alone has become popular in the management of clinical stage I nonseminomatous germ cell testicular tumors (CSI NSGCTT). Efforts to identify patients at high risk of disease progression led to a search for risk factors in CSI NSGCTT. The aim of the present study was to analyse single-centre experience with risk-adapted therapeutic approaches (active surveillance versus adjuvant chemotherapy). From 1/1992 to 12/2013 a total of 431 CSI NSGCTT patients were included in the study and stratified into two groups according to risk-adapted therapeutic approaches. Group A (low-risk CSI NSGCTT) consisted of 276 patients who underwent active surveillance, progression of disease occurred in $46(16.7 \%)$ patients with a median follow-up of 7.2 months. Six patients $(2.2 \%)$ of this group died with a median follow-up of 34.3 months. Group B (high-risk CSI NSGCTT) consisted of 155 patients who were treated with adjuvant chemotherapy, disease progression occurred in two (1.3\%) of them with a median follow-up of 56.2 months. One patient $(0.6 \%)$ died 139.4 months following orchiectomy. Overall survival rate of all CSI NSGCTT patients in both groups was 424/431 (98.4 \%) with median follow-up of 130.4 months following orchiectomy. Surveillance policy is recommended only in patients with low-risk CSI NSGCTT.
\end{abstract}

Key words: testicular cancer, surveillance, adjuvant chemotherapy, disease progression

The introduction of cisplatin-based combination chemotherapy has revolutionized the treatment of metastatic testicular cancer [1]. Considering the high success rate in the salvage of disseminated cancer, it seemed reasonable to propose patients with orchiectomy alone followed by surveillance only [2] for managing clinical stage I nonseminomatous germ cell testicular tumors (CSI NSGCTT). Patients who relapse are treated with systemic chemotherapy, whereas those who do not relapse are spared unnecessary treatment.

The surveillance after orchiectomy alone has gained a lot of popularity in the management of CSI NSGCTT. Preliminary results were enthusiastic $[2,3,4]$, but critical voices arose against general use of this option as a routine management [5]. With longer observation, the relapse rate increased up to $25 \%$ or more after orchiectomy $[6,7]$. Several studies $[5,7,8,9]$ identified statistically significant predictors of relapse in CSI NSGCTT patients who might therefore benefit from a program other than surveillance. Vascular invasion of the primary tumor was the most consistent prognostic feature identified. Predominantly embryonal carcinoma histology and T2-4 stage were also frequently associated with rate of relapse. The results of our previous reports $[6,10,11,12,13]$ indicate, that prognostic factors useful for stratification of CSI NSGCTT patients to different therapeutic approaches may be established. There have been identified risk factors which define a low risk and a high risk group of patients and which have led to a riskadapted approach of treatment favoring surveillance for patients with low risk and chemotherapy for patients with high risk of relapse $[14,15]$.

The aim of presented study was to correlate our own experience with active surveillance and adjuvant chemotherapy, respectively in CSI NSGCTT patients. 


\section{Material and methods}

The cross-sectional study was carried out in a single centre, which is focused on diagnosis and treatment of testicular cancer. The Centre follows-up 1511 patients with testicular cancer, who geographically represent the whole the Slovak Republic (SR). According to the National Cancer Registry approximately 200 incident cases of testicular tumors are diagnosed annually in the SR. The study was carried out from 1/1992 to $12 / 2013$ and included all newly diagnosed patients with CSI NSGCTT ( $\mathrm{n}=431$ patients out of 1275 patients followed-up in that time), who were stratified according to the selected risk factors (presence of vascular invasion) for risk-adapted therapeutic approaches - active surveillance (group A) and adjuvant chemotherapy (group B). Patients with choriocarcinoma component were not included in the study.

Patients were assigned to the particular clinical stages on the basis of physical examination, CT examination of the chest, abdomen and pelvis, postorchiectomy serum levels of tumor markers - alpha fetoprotein (AFP) and human chorionic gonadotropin ( $\beta$-hCG). The criteria for inclusion into CSI were normal values of all these examinations. Informed consent was obtained from all patients and from the defined study cohort (according to inclusion criteria mentioned above) none of the patients was excluded.

All performed diagnostic and therapeutic approaches proceeded according to actual guideline recommendations for patients with testicular cancer $[14,15]$, without intervention by reason of clinical trials and results of examinations and outcomes were consecutively recorded and evaluated.
Group A consisted of 276 patients without vascular invasion in the primary tumor managed by the policy of surveillance, which consisted of a regular follow-up after orchiectomy with tumor markers (AFP, $\beta$-hCG) measurement and abdominal CT scans performed in 3-month intervals in the first year, 6- month intervals for the next 2-5 years, and annually thereafter. Patients who relapsed during follow-up were treated with platinum-based combination chemotherapy - BEP regimen (bleomycin $30 \mathrm{U}$ IV on days 1,8 , and 15 plus etoposide $100 \mathrm{mg} / \mathrm{m}^{2} \mathrm{IV}$ on days $1-5$ plus cisplatin $20 \mathrm{mg} / \mathrm{m}^{2} \mathrm{IV}$ on days 1-5; every 21days).

Group B consisted of 155 patients with vascular invasion in the primary tumor. They were treated with two cycles of adjuvant chemotherapy - BEP regimen (bleomycin $30 \mathrm{U}$ IV on days 1,8 , and 15 plus etoposide $100 \mathrm{mg} / \mathrm{m}^{2}$ IV on days 1-5 plus cisplatin $20 \mathrm{mg} / \mathrm{m}^{2} \mathrm{IV}$ on days $1-5$; every 21 days).

The demographic characteristics of all patients were analysed using descriptive statistics. Continuous variables were compared using independent sample t-test. Survival curves were generated using the method of Kaplan and Meier, and they were compared using the Log Rank test. Statistical analysis was done in Excel and SPSS Statistics Desktop (version 22.0.0). All statistical tests were two-sided and statistical significance was set at a $\mathrm{p}<0.05$.

\section{Results}

Group A: The mean age of 276 CSI NSGCTT patients without vascular invasion at the time of diagnosis was 29.4 years (median 28.5 years, $25-75 \%$ quantile was 24 and 34 years).

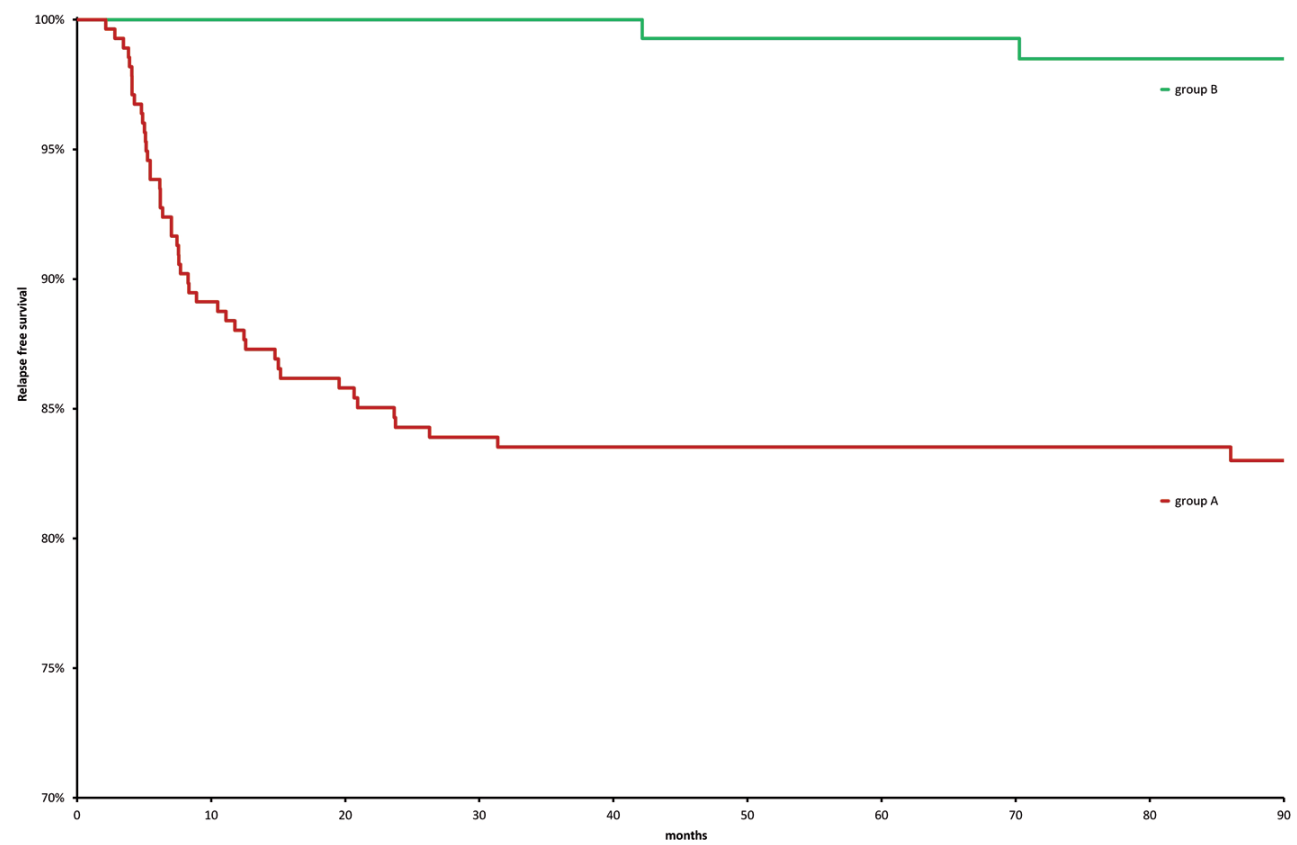

Figure 1. Relapse free survival in patients who underwent surveillance (Group A) and patients who underwent adjuvant chemotherapy (Group B) 
Table 1. Patients characteristics

\begin{tabular}{lcccc}
\hline Descriptive characteristics & Adjuvant chemotherapy & Active surveillance & summa & p value \\
\hline abs. number & 155 & 276 & 291 & NS \\
age-average & 30,9 & 29,4 & 15 & \\
age-min & 16 & 57 & 67 & \\
age-max & 67 & $46(16.7 \%)$ & $48(11.1 \%)$ & p $<0.001$ \\
Relaps rate (\%) & $2(1.3 \%)$ & $6(2.2 \%)$ & $7(1.6 \%)$ & 383 \\
Death rate (\%) & $1(0.6 \%)$ & $230(83.3 \%)$ & 424 & $\mathrm{p}<0.001$ \\
Relapse free survival (\%) & $153(98.7 \%)$ & $270(97.8 \%)$ & & $\mathrm{NS}$ \\
Overall survival (\%) & $154(99.4 \%)$ & & & \\
\hline
\end{tabular}

Relapse occurred in $46(16.7 \%)$ patients with a median follow-up of 7.2 months (mean 11.7, \pm 13.2 months, range 2.1 to 86.0 months). Thirty-two (69.6\%) relapsed in the first year of follow-up. Six patients ( $2.2 \%$ ) of this group died with a median follow-up of 34.3 months (mean 42.8, \pm 31.9 months; range 11.4 to 179.7 months).

Group B: The mean age of 155 patients with CSI NSGCTT with vascular invasion was 30.9 years (median 30, 25-75\% quantile was 24 and 36 years). Relapse was experienced in two $(1.3 \%)$ patients with a median follow-up of 56.2 months (mean 56.2, \pm 19.9 ; range, 42.2 to 49.4 months). One patient (0.6\%) died 139.4 months following primary chemotherapy. Overall relapse rate was $48 / 431$ (11.1\%).

There is statistically significant difference in progression free survival (PFS) between these two groups ( $\mathrm{p}<0.001$ ) (figure 1), but no significant (NS) difference in overall survival (OS). OS rate of all CSI NSGCTT patients in both groups was 424/431 (98.4\%) with median follow-up of 130.4 months (mean 134.4, \pm 68.1 ) following orchiectomy (table 1).

\section{Discussion}

Over the last 35 years the distribution of stage in initial diagnosis of NSGCTT has changed with more patients being diagnosed at earlier stages. Approximately $30-50 \%$ of patients with NSGCTT presented with CSI disease $[15,16]$, according to our results $33.8 \%$ of all patients diagnosed in 1992-2013 in the single-centre was in this clinical stage.

The management of CSI NSGCTT following orchiectomy is controversial and generates the most debate. Options include surveillance (with salvage treatment for relapse), adjuvant cisplatin-based combination chemotherapy, or retroperitoneal lymph node dissection (RPLND). Differentiated managements of CSI NSGCTT patients were studied since the late 80 's to early 90 's $[5,6,7,8,9]$, and were accepted later to the several national and international guidelines $[14,15]$. All mentioned options provide cure rates of approximately $99 \%$ [17]. In the USA, a standard postorchiectomy approach has been nervesparing RPLND, while mainly in Europe, primary surgical approaches have fallen out of favor and nonsurgical approaches now predominate. In our presented study all of 276 patients with low-risk CSI NSGCTT (without vascular invasion) were managed by the policy of surveillance and 155 patients with high-risk CSI NSGCTT (with vascular invasion) were treated with two cycles of BEP adjuvant chemotherapy.

Because only $30 \%$ of patients relapse during surveillance, $70 \%$ of patients who are cured by orchiectomy alone could be unnecessarily exposed to adjuvant treatment-related toxicity. To reduce this overtreatment, the EAU 2009 guidelines [18] advise a "risk-adapted treatment approach" recommending adjuvant treatment only for high-risk cases. The EAU 2009 guidelines [18] propose two cycles of adjuvant BEP chemotherapy to those high-risk patients with pT2N0M0 (with vascular invasion) or pT3-4N0M0, while those low-risk cases (pT1N0M0, without vascular invasion) are recommended to undergo surveillance.

Given that all current strategies for CSI NSGCTT, when carried out well, lead to nearly uniform cure, diminishing treatment-related morbidity has become the primary concern.

Few large European or USA series of non-risk adapted treatment utilising primary active surveillance for all patients with CSI NSGCTT irrespective to risk profile have been reported $[19,20,21]$. There were 59/223 (26\%) relapses with median follow-up of 52 months occured in the Kollmansberger et al. [19] series. Canadian study [20] using non-risk-adapted approach described two cohorts. In the initial cohort (19811992), 53 of 157 patients (33.8\%) relapsed compared with 51 of 214 patients $(23.8 \%)$ in the recent cohort (1993-2005). In our previous non-risk-adapted study [13] we found out $52 / 145(35.9 \%)$ relapses following surveillance used in all CSI NSGCTT patients. Non-risk-adapted surveillance provides excellent survival and reduces the overall treatment burden and potentially the longer-term toxicities of treatment [20]. Nichols et al. [21] argue that adjuvant chemotherapy results in unnecessary treatment for approximately $50 \%$ of the patients with increasing awareness of the long-term risk for cardiovascular diseases and second malignancies attributable to platinum-based chemotherapy. On the other hand, based on the historical literature, active surveillance of all patients with CSI NSGCTT, i.e. without risk stratification, will result in delayed treatment of relapse in up to $30 \%$ of patients, usually with multiple cycles of chemotherapy and surgical resection of residual masses [22]. 
The European current guidelines [14, 15] recommend risk-adapted approach in CSI NSGCTT. The results of large prospective SWENOTECA study [23] described the relapse rate $39 / 228(13.5 \%)$ at a median follow-up of 5.0 years in patients without vascular invasion who chose surveillance. SWENOTECA study [23] showed in patients with vascular invasion receiving one course of BEP 5/157 (3.2\%) relapses at the mean follow-up of 4.8 years. In the present risk-adapted study we observed 46/276 (16.7\%) relapses in the group of patients without vascular invasion following active surveillance. Albers et al. [24] reported results of the largest randomized trial (German Testicular Cancer Study Group) investigating adjuvant treatment strategies in CSI NSGCTT which showed 2/174 (1.2\%) relapses following one course of BEP chemotherapy. A pooled analysis of 13 studies involving 1043 patients revealed a relapse rate of $1.6 \%$ in 6 patients $(0.6 \%)$ dying of disease [25]. We did not use the policy with one cycle of BEP chemotherapy, so we cannot assess the outcome. Given the two cycles of BEP, only $3 \%$ of patients relapsed; therefore, the risk reduction of relapse is $90 \%$ [25]. In our present risk-adapted study we observed 2/155 (1.3\%) relapses in the group of patients with vascular invasion after adjuvant chemotherapy (two cycles of BEP regimen). Recent guidelines of the European Germ Cell Cancer Consensus Group (EGCCCG) recommend active surveillance for low-risk CSI NSGCTT patients and two cycles of BEP chemotherapy for high-risk CSI NSGCTT patients, which are considered the standard treatment option [14].

\section{Conclusions}

Our recent experience confirm the results of other studies, which show the benefit of risk-adapted therapeutic approach in CSI NSGCTT patients. According to the results of this study, we do not recommend the only surveillance policy for all CSI NSGCTT patients, but only for patients with low-risk CSI NSGCTT (without vascular invasion). For patients with high risk CSI NSGCTT (with vascular invasion) we recommend adjuvant chemotherapy. In comparison of non-risk adapted approach and risk-adapted approach after orchiectomy on CSI NSGCTT we observed significant decline of the overall relapse rate from $35.9 \%$ (in the non-risk adapted approach) to $11.1 \%$ (in the risk adapted approach).

Acknowledgements: This publication is the result of the implementation of project APVV-0016-11 supported by the Slovak Research and Development Agency.

\section{References}

[1] EINHORN LH, DONOHUE JP. Cis-diamminedichloroplatinum, vinblastine, and bleomycin combination chemotherapy in disseminated testicular cancer. Ann Intern Med 1977; 87: 293-298. http://dx.doi.org/10.7326/0003-4819-87-3-293

[2] PECKHAM MJ, BARRETT A, HUSBAND JE, HENDRY WF. Orchidectomy alone in testicular stage I nonseminomatous germ cell tumors. Lancet 1982; 2: 678-680.
[3] JOHNSON DE, LO RK, von ESCHENBACH AC, SWANSON DA. Surveillance alone for patients with clinical stage I nonseminomatous germ cell tumors of the testis: preliminary report. J Urol 1984; 131: 491-493.

[4] SOGANI P, WHITMORE WF, HERR HW, BOSL GJ, GOLBEY $\mathrm{RB}$. Orchiectomy alone in the treatment of clinical stage I nonseminomatous germ cell tumor of the testis. J Clin Oncol 1984; 2: 267-270.

[5] THOMPSON PI, NIXON J, HARVEY VJ. Disease relapse in patients with stage I nonseminomatous germ cell tumor of the testis on active surveillance. J Clin Oncol 1988; 6: 1597-1603.

[6] ONDRUS D, HORNAK M. Orchiectomy alone for clinical stage nonseminomatous germ cell tumors of the testis (NSGCTT): a minimum follow-up period of 5 years. Tumori 1994; 80: 362-364.

[7] STURGEON JFG, JEWETT MAS, ALISON RE, GOSPODAROWICZ MK, BLEND R et al. Surveillance after orchiectomy for patients with clinical stage I nonseminomatous testis tumors. J Clin Oncol 1992; 10: 564-568.

[8] KLEPP O, OLSSON AM, HENRIKSON H, AAS N, DAHL O et al. Prognostic factors in clinical stage I nonseminomatous germ cell tumors of the testis: multivariate analysis of a prospective multicenter study. J Clin Oncol 1990; 8: 509-518.

[9] WISHNOW KI, JOHNSON DE, SWANSON, DA, TENNEY DM, BABAIAN RJ et al. Identifying patients with low risk clinical stage nonseminomatous testicular tumors who should be treated by surveillance. Urology 1989; 34: 339-343. http:// dx.doi.org/10.1016/0090-4295(89)90436-6

[10] ONDRUS D, HORNAK M, VRABEC J. Low sperm counts as a prognostic factor of progression in stage I non-seminomatous germ cell testicular tumours. Br J Urol 1988; 62: 82-84. http:// dx.doi.org/10.1111/j.1464-410X.1988.tb04273.x

[11] ONDRUS D, GONCALVES F, KAUSITZ J, MATOSKA J, BELAN V. The value of prognostic factors in the management of stage I nonseminomatous germ cell testicular tumors (NSGCTT). Neoplasma 1996; 43: 195-197.

[12] ONDRUS D, MATOSKA J, BELAN V, KAUSITZ J, GONCALVES F et al. Prognostic factors in clinical stage I nonseminomatous germ cell testicular tumors: rationale for different risk-adapted treatment. Eur Urol 1998; 33: 562-566. http://dx.doi.org/10.1159/000019656

[13] ONDRUS D, ONDRUSOVA M, HORNAK M, MATOSKA J. Nonseminomatous germ cell testicular tumors - clinical stage I: differentiated therapeutic approach in comparison with therapeutic approach using surveillance strategy only. Neoplasma 2007; 54: 437-442.

[14] KREGE S, BEYER J, SOUCHON R, ALBERS P, ALBRECHT $\mathrm{W}$ et al. European consensus conference on diagnosis and treatment of germ cell cancer: a report of the second meeting of the European Germ Cell Cancer Consensus group (EGCCCG): part I. Eur Urol. 2008; 53: 478-496. http://dx.doi. org/10.1016/j.eururo.2007.12.024

[15] ALBERS P, ALBRECHT W, ALGABA F, BOKEMEYER C, COHN-CEDERMARK G et al. Guidelines on Testicular Cancer: 2011 Update. Eur. Urol., 2011; 60: 304-319. http:// dx.doi.org/10.1016/j.eururo.2011.05.038 
[16] COLEMAN S, STEPHENSON A. Controversies in the management of stage I non-seminomatous germ cell tumors. Curr Urol Rep 2013; 14: 506-510. http://dx.doi.org/10.1007/ s11934-013-0362-5

[17] ALBERS P, SIENER, R, KLIESCH S, WEISSBACH, L, KREGE $S$ et al. Risk factors for relapse in clinical stage I nonseminomatous testicular germ cell tumors: results of the German Testicular Cancer Study Group trial. J Clin Oncol 2003; 21: 1505-1512. http://dx.doi.org/10.1200/ LCO.2003.07.169

[18] BREWSTER SF. Challenging the EAU 2009 guidelines on testis cancer: the risk-adapted management of stage I nonseminomatous germ cell tumours: surveillance yields equal results with less toxicity. Eur Urol 2010; Suppl. 9: 459-461.

[19] KOLLMANNSBERGER C, MOORE C, CHI KN, MURRAY N, DANESHMAND $S$ et al. Non-risk-adapted surveillance for patients with stage I nonseminomatous testicular germcell tumors: diminishing treatment-related morbidity while maintaining efficacy. Ann Oncol 2010; 21: 1296-1301. http:// dx.doi.org/10.1093/annonc/mdp473

[20] STURGEON JF, MOORE MJ, KAKIASHVILI DM, DURAN I, ANSON-CARTWRIGHT LC et al. Non-risk-adapted surveillance in clinical stage I nonseminomatous germ cell tumors: the Princess Margaret Hospital's experience. Eur Urol 2011; 59: 556-562. http://dx.doi.org/10.1016/j.eururo.2010.12.010
[21] NICHOLS CR, ROTH B, ALBERS P, EINHORN LH, FOSTER $\mathrm{R}$ et al. Active surveillance is the prefered approach to clinical stage I testicular cancer. J Clin Oncol 2013; 31: 3490-3493. http://dx.doi.org/10.1200/JCO.2012.47.6010

[22] JEWETT MAS, RICHIE JP, ALBERS P. Treatment of nonseminoma: Stage I. In: Laguna MP, Albers P, Bokemeyer C, Richie JP, editors. Cancer of the testis. London, Springer Verlag, 2010, $147-166$

[23] Tandstad T, Dahl O, Cohn-Cedermark G, Cavallin-Stahl E, Stierner U et al. Risk-adapted treatment in clinical stage I nonseminomatous germ cell testicular cancer: The SWENOTECA management program. J Clin Oncol 2009; 27: 2122-2128. http://dx.doi.org/10.1200/JCO.2008.18.8953

[24] ALBERS P, SIENER R, KREGE S, SCHMELZ H-U, DIECKMANN K-P et al. Randomized phase III trial comparing retroperitoneal lymph node dissection with one course of bleomycin and etoposide plus cisplatin chemotherapy in the adjuvant treatment of clinical stage I nonseminomatous testicular germ cell tumors: AUO trial AH 01/94 by the German Testicular Cancer Study Group. J Clin Oncol 2008; 26: 2966-2972. http://dx.doi.org/10.1200/JCO.2007.12.0899

[25] WESTERMANN DH, STUDER UE. High-risk clinical stage I nonseminomatous germ cell tumors: the case for chemotherapy. World J Urol 2009; 27: 455-461. http://dx.doi.org/10.1007/ $\underline{\text { s00345-009-0456-3 }}$ 